\title{
VOLUNTARY SOCIAL INSURANCE POLICY THROUGH THE EVALUATION OF WORKERS IN TAY HO DISTRICT, HANOI CITY, VIETNAM
}

\author{
LINH MAI - THI KIM HOA NGUYEN ${ }^{l}$
}

\begin{abstract}
Vietnam's voluntary social insurance (VSI) policy has been in force since 2008 and by 2018 included 270,000 participants (accounting for 0.79\% of the labor force). Hanoi City is the capital of Vietnam, with 21,156 participants $(0.56 \%)$. The proportion of people participating in VSI is still very low. Workers who have at least 20 years of participation will receive a monthly pension and their beneficiaries will receive a death benefit in case of their demise. The opinions of workers about VSI policies are presented in the report through interviews with 170 voluntary social insurance participants and 168 non-participants in Tay Ho District, Hanoi City. The research results in new findings using comparison between participants and non-participants. In addition, in-depth interviews were conducted with 40 people, including social insurance officials in Tay Ho District, ward officials, and workers, to clarify why the number of VSI participants is low. Based on the research and evaluation of workers concerning VSI policies and regulations, we identify the main causes of this situation, as well as the policyand communication-related shortcomings, and suggest solutions for improving the social insurance participation rate of individuals in Hanoi City in particular, and Vietnam in general.
\end{abstract}

KEYWORDS: policy, voluntary social insurance, workers

\footnotetext{
1 Linh Mai Dr, lecturer of Faculty of Sociology, University of Social Sciences and Humanities, VNU Vietnam, mailinh232000@yahoo.co.uk; Thi Kim Hoa Nguyen PhD, Associate Professor and Director of Center for Social Work Application and Development, Faculty of Sociology, University of Social Sciences and Humanities, VNU Vietnam, kimhoaxhh@yahoo.com. This article is based on the research results of the National University Project in Hanoi "Research and evaluation of the current situation to propose solutions to increase the number of participants in VSI in the informal sector in Hanoi city today." This research is funded by Vietnam National University, Hanoi (VNU) under project number QG.18.43. The article authors are the primary participants of the research topic. The authors would like to thank VNU for sponsorship for conducting this study.
} 


\section{INTRODUCTION}

The provision of social insurance (SI) is a major policy of the Party and state of Vietnam, and a fundamental part of the country's social security system. A resolution of the ninth National Congress of the Party pointed out that: "[w]e have to step by step firmly expand the system of social insurance and social security towards applying social insurance for all workers and all social classes" (Central Party Committee 2014). However, to increase the coverage of SI, increasing uptake of VSI is the most important step. This involves a lot of challenges, as the number of participants is still very limited.

VSI is a type of social insurance organized by the Vietnamese government through which participants are allowed to choose their premium and method of payment in accordance with their income. The government has a policy of supporting SI participants with a pension and death benefit (Social Insurance Law 2014). Participants of VSI may be Vietnamese citizens aged 15 years or older who are not subject to compulsory SI, or workers who are old enough but are not eligible to a regular pension from the SI system, according to the law on SI. From January 1, 2018, VSI participants have been entitled to a pension ranging from $45 \%$ to $75 \%$ of the average monthly income earned during the period of VSI, which corresponds to the number of years of SI contribution in which the SI-related contributions of male workers retiring in 2018 are counted as 16 years, in 2019 as 17 years, in 2020 as 18 years, in 2021 as 19 years, and from 2022 onwards as 20 years. The contributions of female workers who retire from 2018 onwards are counted as 15 years. After that period, each year adds $2 \%$. Regarding the entitlement to a death benefit, the burial allowance is equal to 10 times the basic salary due in the month that the participant of voluntary social insurance dies (the funeral allowance is 13.9 million VND). The survivor allowance is calculated according to the number of years of SI contributions: each year of SI contribution before 2014 contributes an equivalent of 1.5 times the average monthly income, and for the years from 2014 onwards it contributes two times the average monthly income (Article 74, Social Insurance Law 2014)

The VSI system in Vietnam came into force on January 1, 2008. To create this policy, researchers carried out research for 10 years to generate the theoretical and practical basis for developing policies that could promote VSI among workers with a mid- and low level income, with special attention to poor workers and ethnic minority workers (Pham 2012). Informal sector workers are also a matter of concern for many scholars. Studies have shown that more workers in informal sectors come from rural and suburban areas (67.0\%) than from cities. Women account for nearly $50 \%$ of individuals from this sector. The level of education and technical expertise of the labor force is relatively low, as only $15.7 \%$ have 
a high school or higher degree, while over $90 \%$ of workers do not have any skill-related certifications. Moreover, the nature of the work of workers in the informal sector has other noticeable characteristics, such as being precarious and unstable, associated with a low income, a lack of labor contracts, and long working hours. Authors have stated that limitations of VSI policy include the high premiums, long participation period, and low education level of workers - all of which factors affect the latter's awareness of and access to information about the importance of VSI (Bui-Do 2012).

The solutions proposed by the authors include strengthening the promotion of VSI policies, simplifying the administrative procedures in the SI industry and further enhancing the assessment of participation needs and capacity, as well as evaluating the rate of participation among all citizens in general and the poor in particular to make the policy system more appropriate for encouraging the poor and the disadvantaged to participate (Bui-Hoang 2016). A study by Thai (2017) argues that current research in the field mainly considers VSI to be a public policy, but fails to take into account the behavior and intention of participants. In order to measure and evaluate participational intention and behavior related to the uptake of VSI in informal sectors, the authors applied theories and models of behavior such as consumer behavior theory and attitude theory. The survey results show that the factors of 'moral responsibility' and 'communication,' instead of income, are the two most influential factors regarding the intention to participate in VSI among workers in the informal sector. In addition, low education levels also hinder understanding of SI policies. The above research results contributed to the procedure of making further provisions for helping workers to participate in VSI since January 1, 2018 by the State of Vietnam. Despite the new policy, the number of VSI participants has not increased, or has only increased very slowly.

With regard to the factors that previous studies pointed out, we also identified duplicates such as 'communication issues' alongside those that were not mentioned earlier, such as 'payment' and the fact that "the membership benefits of VSI are not as diverse as other commercial insurance." These are useful ideas that we collected from people, based on which we can propose solutions for improving the participation rate and competitiveness of VSI with commercial insurance in Vietnam. The best solution for increasing the VSI participation rate, as suggested in other studies, is improving communication, although there needs to be a change in the method of communication, especially with regard to the occupation and age of employees. Communication can be done via social networks, a very popular means of media nowadays.

In this study, we use Maslow's theory of needs, but we only employ the theory of the need for safety, one of the most urgent needs of humans (an approach 
that previous studies have never used). When low-level needs are met, higher needs arise. Therefore, when researching the VSI participation of workers in the informal sector, it is necessary to base the examination on an assessment of workers' satisfaction of their biological needs so that we can assess the demand for, condition of, and obstacles to VSI participation. In addition, we base the analysis on the theory of rational behavior of George Homans, with the desire to understand workers' perceptions, needs, and ability to participate in VSI related to a consideration of the resources required to enjoy the maximum benefits.

Thus the goal of the study is to make sense of the rate of participation in voluntary social insurance (VSI) in Tay Ho District by using Maslow's theory of needs and rational choice behavior in the exploration. Through assessing the expectations of people with regard to VSI policies, we propose solutions especially in terms of communication - regarding how to improve the awareness of and participation rate in VSI.

This study was conducted in August 2018, after the new policy had been in force for eight months. The media and SI agencies at all levels had propagated the initiative and encouraged people to participate in VSI. During this period VSI was considered a hot topic, since people were then actively discussing VSI policy, which was very convenient for doing research, and at the same time meeting the needs of workers and officials at all levels in the SI industry.

\section{MATERIALS AND METHOD}

As of December 2018, Hanoi's population was 8,215,000 people. Fifty-five percent of the population (i.e. 4.5 million people) live in urban areas, and 3.7 million live in a rural area (45\%). Hanoi has 30 administrative units, including 12 districts, 17 rural districts, and one town with 584 communal administrative units, including 386 communes, 177 wards, and 21 towns (Chinhphu 2018). After 10 years of VSI policy, although the number of participants has grown from year to year, Vietnam only has nearly 200,000 participants, and this number is still too small compared to the potential and objectives of the Social Insurance Agency at all levels. In 2018 there were about 270,000 people participating in voluntary social insurance from a total of about 34 million workers who were non-participants, accounting for a very low rate of $0.79 \%$.

Hanoi City has the second largest population in the country, after Ho Chi Minh City. In 2018, Hanoi's population was about 7.2 million people, of which 3.9 million are of working age, accounting for $54.2 \%$ of the city's population. The number of workers who work in the formal sector, having signed labor 
contracts and being subject to compulsory social insurance, is about 1.5 million people, accounting for $38.46 \%$ of the labor force.

The data show that there is a huge potential labor force for developing VSI participation in Hanoi. In 2008, participation included $0.03 \%$ of total workers. By 2017, after nearly 10 years of implementation, the figure was only $0.56 \%$. The informal labor of Hanoi includes the following groups:

First, those who work in traditional craft villages. Until 2015, Hanoi had over 1,270 craft villages distributed in districts, towns, and rural districts. In particular, there are dozens of industries that are undergoing strong waves of development, such as ceramics, textiles, footwear, sculpture, pearl mosaics, embroidery, silk weaving, lacquer, bamboo and rattan weaving, bronze casting, jewelry, mechanical engineering, sticky rice villages, ornamental plants, and dairy farming.

Second is the group of employees that work in agriculture. After expansion of the administrative boundary on August 1, 2008, agricultural land in Hanoi amounted to about 192,000 hectares, accounting for $57.6 \%$ of the city's land area (Nguyen 2018).

The third group is that of freelance workers - those who are self-employed in small-scale business services at home, or who do short-term day-to-day jobs such as manual work, or work as porters or street vendors. The workers in this group are mainly city dwellers who open their own shops and services at home, or migrants from suburban districts of the city, or from other provinces. Basically, this is a group of people the members of which do not register their businesses, nor sign legal labor contracts. Therefore it is difficult to control or statisticize this group accurately.

With such labor characteristics, the proportion of workers in Hanoi that are eligible for VSI is very large, but the actual participation rate is very low at present.

For this study, we chose the Tay Ho District to survey. By the end of November, 2018, the population of Tay Ho District was 127,565 people, with 41,544 households (Pham 2012). Tay Ho District has eight wards: Buoi, Yen Phu, Thuy Khue, Tu Lien, Quang An, Nhat Tan, Xuan La, and Phu Thuong. Tay Ho District has many informal workers in traditional craft villages. Phu Thuong ward is famous for its sticky rice dishes and peach tree planting, Nhat Tan for planting peach blossom trees, Tu Lien ward for decorational kumquat and bonsai, Buoi ward for Do paper, Quang An ward for lotus tea and for renting houses and villas (about 700 families in this ward lease out their estates to foreigners, with 3000 foreigners residing in the area), Xuan La ward has 1,742 households doing business/trading/services (28.84\%). Tay Ho District thus has many informal workers and well-off households. 


\section{The selection of interview subjects}

We relied on lists of voluntary ST participants provided by the ward's People's Committee. The number of participants in VSI in Tay Ho District is limited, so we chose to interview all participants on the list provided by the district social insurance agency. For non-participants, we selected neighbors who live in the same area as the participants. Our purpose was to select samples from the same residential area of individuals with similar living and working conditions who are beneficiaries of similar policies and show certain similarities in terms of social factors such as education level, employment, income, etc. This convenient method of random sampling may not be optimal, but it is perhaps the most suitable for the conditions of the study. The quantitative sample included 338 individuals (170 VSI participants and 168 VSI non-participants), and the qualitative sample 40 .

We were required to visit the house of each person for an interview, but some people were working away from home, visiting relatives, or traveling. In some cases, the household was in the ward, but the workers lived in another area, thus the number of interviews did not meet our expectations. Moreover, the number of workers participating in VSI fluctuates constantly: when people enter a new labor market they may have a working engagement with compulsory SI, so they stop paying VSI, or vice versa; in some cases, participants quit VSI due to difficult economic conditions. Therefore, the number of workers paying voluntary social insurance changes every month. Sometimes there are people who no longer participate in VSI but remain on the list, thus making it difficult to find and interview subjects.

Table 1. Number of interviews with participants and non-participants of VSI in Tay Ho District, Hanoi City

\begin{tabular}{cccc}
\hline Location & $\begin{array}{c}\text { Number of workers } \\
\text { participating in VSI who } \\
\text { were interviewed }\end{array}$ & $\begin{array}{c}\text { Number of workers NOT } \\
\text { participating in VSI who } \\
\text { were interviewed }\end{array}$ & $\begin{array}{c}\text { Total number } \\
\text { of interviewees }\end{array}$ \\
\hline Tay Ho District together & 170 & 168 & 338 \\
\hline Tu Lien ward & 20 & 30 & 50 \\
\hline Xuan La ward & 20 & 20 & 40 \\
\hline Phu Thuong ward & 30 & 20 & 50 \\
\hline Quang An ward & 17 & 15 & 32 \\
\hline Thuy Khue ward & 23 & 16 & 38 \\
\hline Nhat Tan ward & 13 & 25 & 29 \\
\hline Yen Phu ward & 14 & 15 & 60 \\
\hline Buoi ward & 33 & 27 &
\end{tabular}

Source: Statistics provided by VSI agencies in wards and research data.

CORVINUS JOURNAL OF SOCIOLOGY AND SOCIAL POLICY VOL. 12 (2021) 1 


\section{Demographic features}

The demographic features of the surveyed workers are as follows. In terms of gender, workers in the informal sector are mostly women, therefore the majority of VSI participants are women.

In terms of age, most VSI participants are not young people, with ages typically ranging from 36-45 years old. Non-participants are mostly younger than participants of VSI.

The educational level of workers in the survey area is uneven. At the high school level, $35.9 \%$ of workers participate in VSI, and the rate of nonparticipants is $38.7 \%$. Next is the college level: the proportions of the two groups, respectively, are $32.4 \%$ and $28.6 \%$. Workers with university and postgraduate degrees account for $23.5 \%$ and $23.2 \%$, respectively. A notable proportion of workers have a low level of education (less than high school level).

Table 2. Demographic features of workers participating and not participating in VSI in Tay Ho District, Hanoi City, based on survey data

\begin{tabular}{|c|c|c|c|c|c|}
\hline & \multirow[t]{2}{*}{ Demographic features } & \multicolumn{2}{|c|}{$\begin{array}{c}\text { Workers } \\
\text { participating in VSI }\end{array}$} & \multicolumn{2}{|c|}{$\begin{array}{c}\text { Workers NOT } \\
\text { participating in VSI }\end{array}$} \\
\hline & & $\mathrm{N}$ & $\%$ & $\mathrm{~N}$ & $\%$ \\
\hline \multirow[t]{2}{*}{ Gender: } & Male & 61 & 35.9 & 56 & 33.3 \\
\hline & Female & 109 & 64.1 & 112 & 66.7 \\
\hline \multirow[t]{3}{*}{ Age: } & $<35$ years & 49 & 28.8 & 87 & 51.8 \\
\hline & $36-45$ years & 82 & 48.2 & 44 & 26.2 \\
\hline & 46 years and older & 39 & 22.9 & 37 & 22.0 \\
\hline \multirow[t]{4}{*}{ Education: } & : High school and lower & 14 & 8.2 & 16 & 9.5 \\
\hline & High school & 61 & 35.9 & 65 & 38.7 \\
\hline & Vocational training/ College & 55 & 32.4 & 48 & 28.6 \\
\hline & University/ Postgraduate & 40 & 23.5 & 39 & 23.2 \\
\hline \multicolumn{2}{|c|}{ Occupation: Sales/ trading } & 62 & 36.5 & 84 & 50.0 \\
\hline \multicolumn{2}{|c|}{ Office workers } & 30 & 17.6 & 31 & 18.5 \\
\hline \multicolumn{2}{|c|}{ Freelancers } & 58 & 34.1 & 46 & 27.4 \\
\hline & Unemployed/ housewife & 20 & 11.7 & 7 & 4.1 \\
\hline \multicolumn{2}{|c|}{ Marital status: Married } & 150 & 88.2 & 123 & 73.6 \\
\hline \multicolumn{2}{|c|}{ Single } & 16 & 9.4 & 33 & 19.8 \\
\hline \multicolumn{2}{|r|}{ Divorced } & 4 & 2.4 & 8 & 4.8 \\
\hline \multicolumn{2}{|r|}{ Widowed } & 0 & 0.0 & 3 & 1.8 \\
\hline \multicolumn{2}{|l|}{ Total } & 170 & 100.0 & 168 & 100.0 \\
\hline
\end{tabular}

Source: Statistics provided by VSI in wards and research data. 
Comparison of the demographic structure gives us some findings:

- There is an age difference between two groups: among people under 35, the proportion of people participating in VSI accounts for only $28.8 \%$. It seems that the older people are, and the more stable their income, the greater their desire to participate in VSI, as compared to young people.

- Marital status is also a relevant factor: the majority of people who participate in VSI are married. They may be interested in VSI because they are more worried about the future, and when participating in VSI, they tend to join in households to ensure they receive benefits, as well as discounts.

In terms of occupation, the Workers we surveyed were in a variety of jobs, but mainly sales and freelance. Due to the characteristics of freelance labor, the situation of being 'between jobs' was quite common in both groups. Regarding marital status, married people accounted for $88.2 \%$ of participants, and $73.6 \%$ of non-participants.

In addition, the project involved conducting 40 in-depth interviews, including with the following individuals: one official of Tay Ho District SI; one cadre in charge of collecting VSI in the ward; three vice-presidents in charge of culturesociety in Tu Lien, Xuan La, and Phu Thuong; five cadres who collect VSI in Tu Lien, Xuan La, Phu Thuong, Nhat Tan, and Quang An wards; fifteen Workers participating in VSI in eight wards; and fifteen Workers who were not participating in eight wards, for the purpose of comparison.

The questionnaire consisted of three parts: (1) a general information section, including questions about demographic data such as gender, education level, income, employment, etc.; (2) a second part about the status of participation, including questions about the reasons for participating/not participating in VSI and respondents' assessment of the VSI policy (premium rate, benefits, time of payment etc.; (3) while the third included questions about people's expectations, and suggestions for changes and solutions for improving the VSI participation rate.

In-depth interviews were built differently for each group of subjects (residents, ward officials, and social insurance officers). The in-depth interviews panel for residents is also divided into three parts, similarly to the questionnaire described above. VSI officials and officers who implement social insurance were addressed in a detailed in-depth interview in connection with VSI policy and solutions for overcoming difficulties with improving the VSI participation rate.

The above-described quantitative and qualitative sample size is appropriate for analyzing the workers' evaluation of VSI policies.

Before analyzing VSI policy through the opinions of people in Tay Ho District, Hanoi City, we assessed the number of workers participating in VSI in the whole 
country and the whole city of Hanoi to be able to give readers more general information about VSI participation.

\section{RESULTS: THE EVALUATION OF WORKERS IN TAY HO DISTRICT, HANOI CITY, CONCERNING VOLUNTARY SOCIAL INSURANCE POLICIES}

\section{Respondents' evaluation of the appropriateness of voluntary social insurance policy regulations}

The rate of participation in compulsory SI was not yet total, but remained stable at a high level (approximately 80\%). It can be said that this stable status reflects the great efforts of the industry and strong coordination among departments that deal with a huge amount of work.

The maintenance and settlement of compulsory SI requires the whole industry to join hands - departments and officials are always overloaded. The resolution of policy issues requires accuracy and thoroughness in relation to individuals and collectives to ensure benefits for participants. We are sometimes overloaded because of heavy workloads, and overtime or weekend work is very normal. In contrast to compulsory SI, VSI seems like a 'stepchild' in the family. While in fact the policies of compulsory health insurance and social insurance are always identified as the main responsibilities of the whole sector, VSI only receives rather superficial attention. (Nam, Social Insurance Officer, Hanoi)

According to Resolution No. 28-NQ/TW dated May 23, 2018, in 2030, the number of farmers and workers participating in VSI will account for about 5\% of the labor force (Government 2018) - a fairly modest plan, but quite realistic. Hanoi is one of the cities with a large concentration of workers in the informal sector, but the proportion of workers participating in VSI in Hanoi is less than the national average.

From a social perspective, the voluntary participation of workers in social insurance contributes to maintaining social stability, helping balance the social security network, and ensuring a basic living standard for workers at retirement age. In general, workers in the survey area strongly appreciate voluntary social insurance policies and related factors. Specifically, 92.4\% of participants 
assessed the targets of voluntary social insurance as appropriate, premiums $91.8 \%$; payment location $90.0 \%$; payment method $88.2 \%$; payment time $87.6 \%$; and attendance records $85.9 \%$.

Table 3. Evaluation of participants concerning the appropriateness of VSI policy regulations

\begin{tabular}{ccccccc}
\hline \multirow{2}{*}{ Regulations } & \multicolumn{2}{c}{ Appropriate } & \multicolumn{2}{c}{ Not appropriate } & \multicolumn{2}{c}{ No answer } \\
\cline { 2 - 7 } & $\mathrm{N}$ & \multicolumn{1}{c}{$\%$} & $\mathrm{~N}$ & $\%$ & $\mathrm{~N}$ & $\%$ \\
\hline Targeted participants & 157 & 92.4 & 2 & 1.2 & 11 & 6.4 \\
\hline Insurance premiums & 156 & 91.8 & 6 & 3.5 & 8 & 4.7 \\
\hline Payment method & 150 & 88.2 & 7 & 4.1 & 13 & 7.7 \\
\hline Payment time & 149 & 87.6 & 10 & 5.9 & 11 & 6.5 \\
\hline Attendance record & 146 & 85.9 & 9 & 5.3 & 15 & 8.8 \\
\hline Benefits & 109 & 64.1 & 47 & 27.6 & 14 & 8.3 \\
\hline Payment location & 153 & 90.0 & 5 & 2.9 & 12 & 7.1 \\
\hline State support for participants & 78 & 45.9 & 40 & 23.5 & 52 & 30.6 \\
\hline Source: Project research results & & & & & &
\end{tabular}

Thus, this shows that the provisions of the Law on Social Insurance concerning voluntary social insurance are somewhat appropriate in practice and are highly appreciated by workers. The targets of voluntary social insurance are not only workers with labor contracts with less than one-month terms and non-specialized employees working in residential quarters, workers working for their own families, farmers, and freelancers. They also include workers who are old enough but not qualified in terms of their contribution period to receive a pension. From 2016 onwards, if the participant has a social insurance premium of no more than 120 months, they will be allowed to compensate for a full 20 years so they can enjoy a pension. The contribution will be paid once to cover the missing years, provided that the social insurance participants are old enough to receive the prescribed pension, so this regulation is appreciated by workers. The regulations dictate that participants can choose to pay monthly, quarterly, six-monthly or annually, thus helping create favorable conditions for workers to participate more easily than if they were required to pay monthly. Thus, the current regulations concerning payment methods are favored by the majority of workers who are involved in the system.

In the past, there was no VSI because when I quit my job, social insurance was settled at once, so I would not have had a pension when I retired. Now, there is a voluntary social insurance policy that continues paying, so old people will have a monthly pension which is also an amount they can spend. Diversified, monthly, and quarterly 
payment methods help workers like us easily choose.... The premium is also suitable in relation to income, if anyone has difficulty, they can pay a few hundred thousand, depending on their condition. (male, security guard, Nhat Tan ward, Tay Ho District, Hanoi)

The new policy introducing voluntary social insurance under the provisions of the new Social Insurance Law now allows workers to freely and easily participate in and enjoy social security policies, contributing to increasing the coverage of these policies. Thus, rational choice behavior theory is shown to operate here quite clearly - the rationalist claim is that individuals normally choose the action that has the greatest probability of yielding results. VSI policy has been supplemented in terms of methods, premium levels, and benefits to best suit the conditions and circumstances of those individuals who participate in VSI. The decision to participate is considered very carefully by people based on many factors, such as policy and economic conditions. However, in terms of benefits, only $64.1 \%$ of workers rated the latter as appropriate, and $8.3 \%$ did not know/did not comment; the level of state support for participants was also evaluated as low (45.9\% said it was adequate). Of note is that up to $30.6 \%$ of respondents did not know about the state support for voluntary social insurance participants, which was implemented in 2018.

Figure 1. Level of satisfaction among VSI participants in relation to benefits (\%)

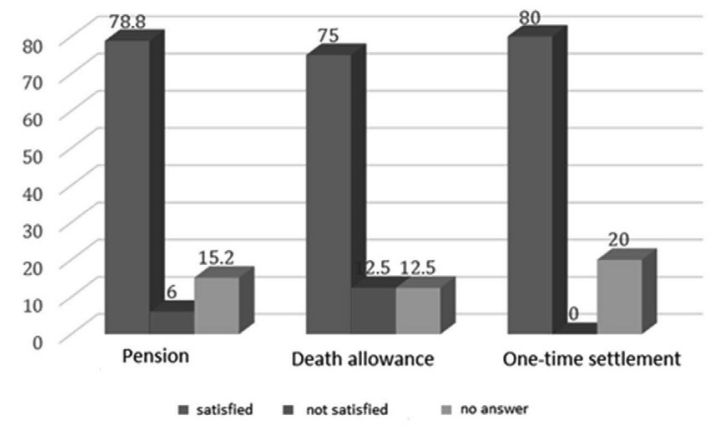

Source: Research results

The above table shows that workers strongly appreciate the benefits that workers or family members receive. In terms of retirement benefits, workers rated satisfaction as very high $(78.8 \%)$, while the death benefit was evaluated by $75 \%$ as satisfactory and the one-time settlement $80 \%$. 
In the past, I participated in social insurance in the district, in all paperwork procedures - the officers at the district social insurance agency explained very carefully and enthusiastically. I am very pleased with the attitude of the staff.

(female, 45 years old, Meeting Room Assistant, Phu Thuong Ward, Tay Ho District, Hanoi)

Besides positive comments, workers also expressed dissatisfaction in relation to a number of factors, such as the pension-distribution locations and pension receipt procedures.

I would not complain about the attitude of the staff or the policy. I participated in VSI in the form of compensating for the missing years so I could receive a pension. When I finished, I received a salary. The following month, I was very excited. The only thing is that the payroll location is a bit cramped, crowded with people waiting, but there are only two payrolls, so they have to wait all day.

(female, 56 years old, Buoi ward, Tay Ho District, Hanoi)

Procedures for getting a pension are complicated and we have to wait for a long time. My father is old, so he has to authorize me to go to get his monthly salary, but the authorization papers have to be renewed every year, which is very time-consuming and expensive.

(Nam, 1976, Xuan La ward, Tay Ho District)

Currently, the district has two methods of pension payment - one is through the postal system, and the other is payment via ATM card. For the payment of pensions by post, the post office had a monthly pension plan at the beginning of the year, but in fact there have been regular changes to the system.

I get my pension at the post office. Every five months I go to the ward cultural house to receive a pension issued by postal officials. But there was a time when the post office changed the date lof the time of collection] but only posted the notice at the ward office, so many people who did not know about the salary had their effort wasted.

(Nam, 64 years old, Buoi ward, Tay Ho District, Hanoi)

Thus, the qualitative research results suggest that there are still some inadequacies that cause trouble for people regarding their pension payment, as analyzed here. 


\section{Supplementation of VSI policies}

Through the quantitative survey we collected the suggestions of workers who did not participate in voluntary social insurance. Their opinions both express their own needs and those of their families in particular, and indicate desire for changes in voluntary social insurance policies in general.

Figure 2. Opinions of non-participants concerning how to supplement VSI polices (\%)

Opinions on supplementation of SI regulations

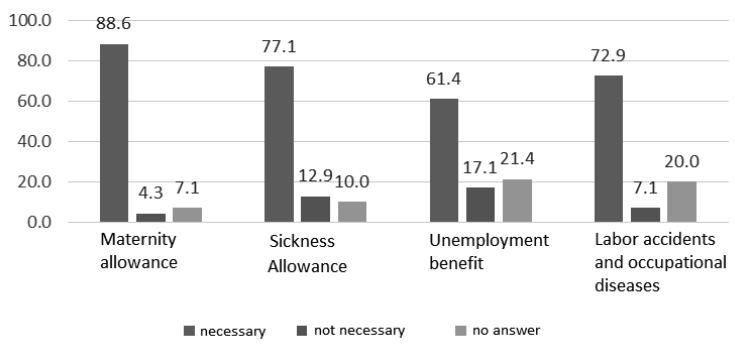

Source: Research results

Looking at the participants' expectations about supplementing the voluntary social insurance policy, the results are as follows: up to $88.6 \%$ of respondents suggested introducing a maternity allowance, followed by a sickness allowance (77.1\%), one for labor-related accidents and occupational diseases $(72.9 \%)$, and unemployment benefits (61.4\%) (Figure 2).

The workers who participate in voluntary social insurance have many ideas connected to representing their interests.

The targets of participation, premiums, methods of payment, records ... are all appropriate, only the benefits of workers are not appropriate - we should add a benefit for women who give birth. I expect the state to supplement maternity benefits. However, with different levels of benefits, the contribution level must be different between women and men, as men are not subject to receiving the maternity allowance. (female, 33 years old, university diploma, salesperson of Western medicine, Tu Lien ward, Tay Ho District, Hanoi) 
The state should consider adding a maternity allowance - at least there should be allowances for women who give birth, as only then will people participate. It does not have to be much, but there should be a sum for women so they do not feel like parasites, thus encouraging women of working age to participate.

(female, university diploma, LISA cadre in Phu Thuong ward, Tay Ho District, Hanoi)

Considering the gender correlation, results show that women are more liable to suggest a supplement than men regarding all four types of VSI benefits, especially maternity benefits $(81.6 \%$ compared to $70.4 \%)$. A labor-related accident and occupational disease benefit ranks second (65.5\% and $72.4 \%)$.

I think we should add maternity and occupational accident and disease benefits. Because workers like us work in unsecured conditions, there are no labor contracts. In unfortunate cases, having an accident at work but being supported by the voluntary social insurance policy is much better.

(male, 1972, university diploma, Xuan La ward, Tay Ho District, Hanoi)

I think the state should supplement maternity benefits. If voluntary social insurance provides these benefits, it will attract more women participants, because the maternity allowance is both a financial encouragement but also a spiritual encouragement for women. If postpartum women receive support from the state, and also for their children, life will be less hard and much less stressful.

(female, 29 years old, university diploma, Buoi ward, Tay Ho, Hanoi)

Thus, although not really a key condition, benefits are still among the important factors to be considered when workers participate in voluntary social insurance. The need for additional benefits is captured in the wishes and aspirations of people in relation to VSI policies. Above all, this stems from the need for safety, as described in Maslow's theory of needs. This need ranks at the second level, above physiological need, and is connected to the security of health, finance, life, and body. People's decision to invest in voluntary social insurance is clearly affected by health-related, financial, and stage-of-life factors (e.g. in relation to the death benefit of the VSI), as well as a need for psychological assurance in times of unexpected incidents. 
Several times I heard the head of the residential area encouraging us to join VSI, but actually considering the long membership period and the benefits, we are very confused. My family currently uses Manulife insurance. Although the premium is higher, the benefits are very diverse, they have a sickness and accident regime, so I still feel more secure. (female, 52 years old, high school diploma, Quang An ward, Tay Ho District)

Thus, although there are different perceptions and needs among age groups, VSI participants are very interested in including more benefits in VSI participation, especially maternity benefits for female workers. This is also a drawback of VSI compared to the commercial insurance on the current Vietnamese market.

\section{Communication about VSI}

Sources of information about VSI for workers in the survey area are diverse. However, workers mainly obtain information from local government (47.6\%), 35.9\% from social insurance agencies, $22.9 \%$ from family/ relatives/ acquaintances, while media only accounted for $27.6 \%$ and poster leaflets $5.9 \%$. This shows that the communication activities of the local government about voluntary social insurance - directly from SI-collecting agents - have had a partly positive effect, while the impact of mass media has been quite fuzzy in terms of communicating about VSI.

Data show that for the age group 35 and under, the proportion of workers accessing information about SI is $26.1 \%$. For the $36-45$ age group, the rates are $48.7 \%$ and $47.3 \%$, respectively. For the age group 46 years of age and above, the rate is $25.2 \%$ and $18.2 \%$. However, data on the age group correlation also showed that workers aged 36-45 years obtained more information on VSI than other age groups.

In middle age, workers have a family and stable income, but health conditions are affected, and much reduced. Workers pay a lot of attention to obtaining benefits for themselves when they gradually reach retirement age, so they often find out information about VSI and health insurance through various sources, such as officials from the SI agency or government, unions, and mass media and the internet. (male, representative of Xuan La ward, Tay Ho District, Hanoi) 
In terms of gender, the proportion of women accessing information on voluntary social insurance is larger than that of men (the proportion of women is $63.5 \%$ and that of men is $36.5 \%$ ).

Regarding education level, for those with a high-school education or less, the rate of access to information about voluntary social insurance is quite high, at $52.2 \%$, followed by those with a vocational and college education (27.0\%), while individuals with a university or postgraduate degree are least likely to seek out information (20.9\%).

Similarly to the rate of information access, $47.6 \%$ of respondents say that when they have questions they ask local government officials - namely, officials/ experts who are agents for collecting VSI. The proportion of people who turn to VSI officials with questions is large, at $63.5 \%$, while $17.1 \%$ ask questions from friends/ acquaintances. However, with non-urgent cases, workers, especially young workers, often refer to the internet, using the website of the Vietnam Social Insurance Agency, Hanoi Social Insurance, or websites specialized in addressing legal matters. Accessing help from social workers, legal consultancy centers, and the 1080 switchboard is not an option chosen by many people.

Workers who have not participated in VSI also gave us some of their opinions about the effectiveness of forms of voluntary social insurance.

Figure 3. Means of communication accessed by non-participants of VSI (\%)

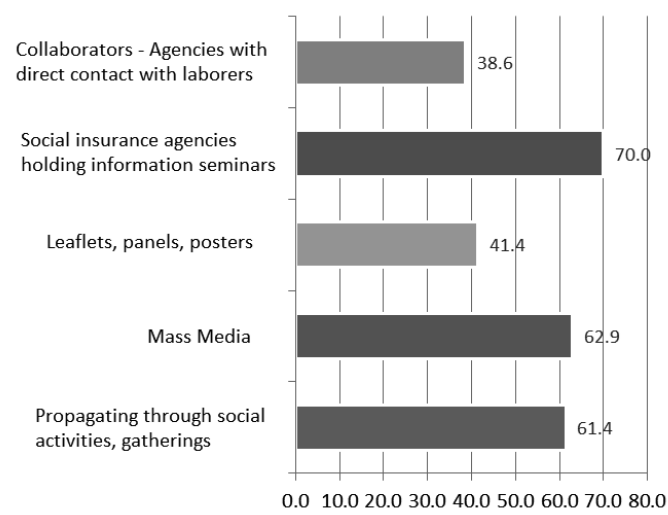

Source: Research results

The chart above shows that the means of accessing forms of communication about voluntary social insurance are quite diverse. The most frequently chosen option is 'mass media' (62.9\%), followed by 'Propagating through social activities and gatherings' (61.4\%) while the least popular are 'poster, panels 
and leaflets' (41.4\%) and 'collaborators and agencies with direct contact' $(38.6 \%)$.

It is clear that with young workers nowadays, communication via traditional mass media such as newspapers, radio, and even television is no longer suitable. Everyone has a smartphone, so communication about VSI must catch up with this trend to be effective.

(male, LISA cadres, Tay Ho District)

In the opinion of workers, mass media such as the internet, especially social networks, are information channels very frequently accessed by people of all classes and ages, so the active dissemination of information about VSI through these media will help communicate information to people as quickly as possible.

I've been retired for 10 years but I still keep up to date with the news. Two years ago, my son bought me a touch phone, which is very convenient. Since then, I have also read fewer books and accessed fewer radio stations. Information about VSI is mostly propagated on newspapers and radio, so I do not know it very well.

(male, university diploma, Xuan La ward, Tay Ho District, Hanoi)

Therefore, the selection of methods and forms of communication should be appropriate for the conditions and actual situations of each subject and household. Being faced with the 4.0 era and the use of technology for serving daily needs, media also need to change to suit the needs of people.

I see that if information on the policies and benefits of voluntary social insurance is propagated via means such as television and social networks, it is possible to reach people very quickly and effectively. (male, high school diploma, Tu Lien ward, Tay Ho District, Hanoi)

Accessing information about voluntary social insurance through mass media is the preferred option among workers who are non-participants, which is quite understandable as access to mass media is currently quite convenient and easy. In particular, all the workers responded that they had at least one social network account such as Facebook, Zalo, or Viber, etc. Accordingly, we propose that sending information through social networks could promote the social insurance policy in the coming years and help workers obtain access to and have a better understanding of the related policy. 


\section{DISCUSSION}

Voluntary social insurance is a new form of insurance with many advantages. It can give workers the opportunity to participate in social insurance, receive a pension in retirement, and reduce the difficulties and risks associated with aging. The research results show that the demand from workers to participate in voluntary social insurance in Tay Ho District is strong, and this demand increases with age. The number of older workers who desire voluntary social insurance is greater than that of the young, and there are those who have participated in social insurance but were forced to switch.

The number of people participating in voluntary social insurance is tending to increase, but only very slowly, and the level of active participation of workers is not high. Participants mainly participate directly by paying money to benefit from the policy; however, accessing information is limited; and contributing opinions regarding amending and supplementing policies is infrequent. The main difference between participants and non-participants lies in the fact that new participants who used to participate in VSI but for an insufficient number of years need to participate for a few more years to receive any benefits. As such, it is actually old participants who now re-join, not new participants. Increasing the new participation rate is still a big challenge

For workers who are traders and freelancers in the district, the economic factor is not the main determinant of VSI participation. Workers who participate in VSI strongly appreciate the method of payment, payment rates, payment location, and participation records. Rational choice behavior theory partly explains individuals' motives and purposes for participating in VSI. However, the problems of contribution time and benefits (only two benefits: retirement pension and a death benefit) cause many workers to be worried and afraid. The motivation for participating in VSI is derived from the need for security (health, financial, life and non-injury) - some of the important needs that Maslow mentioned in his theory of needs.

This study has obtained quite different results from previous studies by identifying that the low level of contribution and education level are not the decisive factors in the decision to participate in VSI. Also, it has identified people's desire for other benefits and other forms of communication by VSI agencies. In order to improve VSI participation in Tay Ho District, there are many measures that need to be taken. These especially include strengthening communication about the benefits of VSI through currently popular forms of media such as the internet and social networks. 


\section{REFERENCES}

Bui, S. T. - M. T. Hoang (2016a) Voluntary social insurance: Opening more opportunities to ensure social security for the poor. Journal of Social Insurance, March 1, 2016, pp. 19-21.

Bui, S. T. - M. T. Hoang (2016b) Applying marketing to develop voluntary social insurance. Journal of Social Insurance, April 2, 2016, pp. 15-17.

Central Party Committee (2014) Resolution of the 9th Conference No. 33 NQ/TW.

Central Executive Committee (2018) Resolution of the 7th Central Committee Session XII.

Chinhphu, T. (2018) Every year Hanoi's population increases equivalent to a large district. Thoi Bao Taichinh - Vietnam Online, October 18, 2018, http:// thoibaotaichinhvietnam.vn/pages/xa-hoi/2018-10-18/moi-nam-dan-so-hanoi-tang-tuong-duong-mot-huyen-lon-63276.aspx [Last access: 0330 2019]

Duong, V. T. (2014) Innovating and developing Social Insurance in Vietnam, Hanoi. Ho Chi Minh City (Vietnam), Information Culture Publishing House Government (2015) Decree No. 1342915/ND-CP, December 29, 2015, Hanoi

Government (2018) Resolution No. 28-NQ/TW on Social Insurance Policy Reform. May 25, 2018, Hanoi

Government (2018) Report on the Implementation of Social Insurance Policies and Benefits Management and Use of Social Insurance Fund in 2017, No. 166 / BC-CP. May 10, 2018

Labor Code (2012) Labor Code No. 10/2012/QH13 of the National Assembly. June 18, 2012.

Ministry of Labor (2007) Invalids and Social Affairs in Association with the World Bank. Ministry-level project 'Survey on the prospect of voluntary social insurance for the informal sector in Vietnam: Recommendations and policies'.

Nguyen, P. (2018) Hanoi: Increase in agricultural production in 5 years averagely increased by 2.23\%. Thoi Bao Taichinh - Vietnam Online, September 27, 2018. http://thoibaotaichinhvietnam.vn/pages/kinh-doanh/2018-09-27/ha-noi-giatri-gia-tang-san-xuat-nong-nghiep-5-nam-tang-binh-quan-223-62456.aspx [Last access: 1117 2019]

Nguyen, T. K. H. - T. T. N. Nguyen (2018) Current situation of workers participating in voluntary social insurance. Research in Tay Ho District and Dong Anh District, Hanoi. Sociology Journal, No. 3 (143), pp. 118-128.

Nguyen, X. M. - N. M. T. Tran (2014) Informal economic sector from economic sociological perspective. Sociology Journal, No. 1, (125), 2014.

Pham, D. N. T. (2014a) Proposals to complete the policy of voluntary social insurance. Social Insurance Magazine, No. 256, pp. 16-18. 
Pham, D. N. T. (2014b) Proposals to complete voluntary social insurance policy. Social Insurance Magazine, No. 257, pp. 12-14.

Pham, T. D. (2015) Orientation to improve social security and social welfare policies in our country under new conditions. State-level project code KX.04.17/ 11-15.

Pham, X. N. (2012) Social security system in Vietnam during the renovation period. Sociology Journal, Issue 2, (118).

Social Insurance Law (2014) Social Insurance Law No. 58/2014/QH13 of the National Assembly. November 20, 2014

Tay Ho District Police (2018) Report of Household Income Data as of November 15, 2018 by Tay Ho District Police

Thai, D. (2017) For informal workers to access social insurance and health insurance policies. Social Insurance Magazine, Issue: November 1, pp. 22-39. 